\title{
The application of the QALY measure in the assessment of the effects of health interventions on an older population: a systematic scoping review
}

\author{
Ewa $\operatorname{Kocot}^{1^{*}}$ (D), Paulina Kotarba ${ }^{2}$ and Katarzyna Dubas-Jakóbczyk ${ }^{1}$ (B)
}

\begin{abstract}
Background: One of the most commonly used types of evaluation methods is cost-utility analysis (CUA), using the Quality Adjusted Life Year (QALY) indicator as a preference-based measure for assessing effects of a given programme. Such assessments are often translated into health-care provision priorities; therefore, effectively choosing the method of outcome evaluation is crucial for ensuring the best possible allocation of scarce resources. The main objective of this scoping review is to identify what kinds of problems and limitations may occur when the QALY indicator is used to assess the effects of health interventions in the older population.

Methods: To identify literature in a scoping review, the databases MEDLINE via PubMed and Scopus were searched. A manual search on relevant organizations' and associations' websites was also conducted (EUnetHTA, ISPOR and national governmental agencies responsible for allocation decisions). No limits concerning publication dates were set. All relevant data were extracted and analyzed, then a narrative summary was prepared.

Results: The database search identified 10,832 relevant items, finally 32 studies were included in the analysis. The main types of issues indicated in the studies were as follows: (1) lower life expectancy in the older population causes lower QALY gains; (2) an equal value of one QALY is used regardless of age; (3) poorer average health state causes lower QALY gains; (4) inadequate instruments to measure quality of life (QoL); (5) attributes of QoL used regardless of age; and (6) no beyond-health QoL aspects taken into account.

Conclusions: This review shows clearly that many problems of different types are connected with using QALY for the older population, but there is no consensus as to whether QALY discriminates against the older population or not - an opinion regarding this issue depends strongly on accepted principles, particularly the approach to equity and how one understands fairness. Health care resources should not be allocated solely on the basis of the health maximization rule because this can lead to discrimination against certain groups (e.g., older, disabled, and/or chronically ill people). To maintain the balance between efficiency and equity, the issues connected with age-based rationing should be widely discussed.
\end{abstract}

Keywords: Quality adjusted life year (QALY), Older population, Resource allocation

\footnotetext{
* Correspondence: ewa.kocot@uj.edu.pl

${ }^{1}$ Health Economics and Social Security Department, Institute of Public Health,

Faculty of Health Sciences, Jagiellonian University Medical College, Krakow,

Poland

Full list of author information is available at the end of the article
}

C C The Author(s). 2021 Open Access This article is licensed under a Creative Commons Attribution 4.0 International License, which permits use, sharing, adaptation, distribution and reproduction in any medium or format, as long as you give appropriate credit to the original author(s) and the source, provide a link to the Creative Commons licence, and indicate if changes were made. The images or other third party material in this article are included in the article's Creative Commons licence, unless indicated otherwise in a credit line to the material. If material is not included in the article's Creative Commons licence and your intended use is not permitted by statutory regulation or exceeds the permitted use, you will need to obtain permission directly from the copyright holder. To view a copy of this licence, visit http://creativecommons.org/licenses/by/4.0/. The Creative Commons Public Domain Dedication waiver (http://creativecommons.org/publicdomain/zero/1.0/) applies to the data made available in this article, unless otherwise stated in a credit line to the data. 


\section{Background}

Resource allocation in the health care sector requires (and will require in the future) decision-makers to make difficult decisions about setting priorities. To provide evidence-based indications for making these decisions, economic evaluations comparing the costs and effects of various health programmes are increasingly prevalent $[1$, $2]$. One of the most commonly used type of evaluation method is cost-utility analysis (CUA), using the Quality Adjusted Life Year (QALY) indicator as a preferencebased measure for assessing effects of a programme. The main advantage of QALY is that it combines in a single indicator the measurement of quality of life (QoL) and the length of life. As QALY can be calculated for nearly every kind of treatment, intervention, or procedure, this indicator has a high comparative potential and is widely accepted as enabling comparison of health benefits [3]. The QALY measure is recommended or even mandatory in health technology assessment procedures in many countries [4]. It is used to assess the effects of health programmes in all age groups, from the youngest to the oldest. However, the question arises of whether the results presented in QALY are really fully comparable between populations of all ages, without any bias.

During the QALY calculation, both health status (in terms of QoL) and length of life are taken into account. In the case of older people, health status is usually worse and life expectancy is shorter than for younger people; so, looking at the QALY construction, it can be expected that the programme benefits assessed by this method will usually be valued lower for the old.

Such assessments are often translated into health-care provision priorities; therefore, effectively choosing the method of outcome evaluation is crucial for ensuring the best possible allocation of scarce resources. Traditionally, the lowest cost per QALY is an indication for prioritization with the aim of maximizing health gain in the population [5]. However, growing evidence shows that the rule of health gains maximisation is not sufficient when making allocative decisions. Equity and fairness issues are also important and equity weighing should be incorporated into allocative decisions as they may have enormous ethical consequences [5, 6]. From a societal point of view, some health gains (which can also be presented in the QALYs) can be considered to be more valuable for the general population than others [7]. The issue of how to reconcile different preferences in allocation decisions with traditional economic evaluation indications is still under debate [5, 7-9].

QALY has been broadly criticized in the literature due to many problems that arise during the calculation process (e.g. [10-15]). Among other things, the QoL assessment, an integral part of this process, requires a valuation of health states. However, perception of health and diseases may vary significantly between people and a lot of heterogeneity can emerge in this assessment. Additionally, there is no general consensus as to which dimensions of human life should be taken into account when assessing QoL, and considering all significant ones is not technically possible. There are also many problems regarding equity consideration when decisions are made in line with results of analyses based on QALY. Not all issues connected with QALY concern the older population specifically and they may impact the results of the economic evaluation differently for different age groups. The main objective of this research is to identify what kind of problems and limitations may occur when the QALY indicator is used to assess the effects of health interventions in the older population. To the authors' knowledge, based on quick database reviews, no extended review related to this topic, and focused specifically on the older population, has been done so far.

\section{Methods}

A scoping literature review was conducted, based on the methodological framework outlined by Peters et al. [16]. This project has been registered through the Open Science Framework.

\section{Research questions}

To achieve the general objective of this study, three specific research questions were defined:

1. What type of research has been done to identify the relevant issues?

2. What kinds of problems can arise when applying the QALY indicator for the older population?

3. What solutions the identified problems have been proposed and what recommendations have been formulated?

\section{Search process}

To identify literature, the databases MEDLINE via PubMed and Scopus were searched. A manual search on relevant organizations' and associations' websites was also conducted (EUnetHTA, ISPOR and national governmental agencies responsible for allocation decisions). Finally, the reference lists of included publications were scanned to identify interesting items. No limits concerning publication dates were set. The database searches were conducted on February 16th 2021. Internet websites of organizations and projects were screened in April 2021. The further analysis took place in May and June 2021.

There were two groups of search terms defined: (1) indicator (QALY) and (2) population (older). The Boolean operator "OR" was used between terms inside each 
group and the groups were then connected by the Boolean operator "AND".

Two groups of search terms were defined:

\section{(1) indicator}

MEDLINE by PubMed: QALY OR "Quality

Adjusted Life Year*" OR qaly [MeSH Terms].

Scopus: ALL (QALY) OR ALL("Quality Adjusted Life Year*")

\section{(2) population}

MEDLINE by PubMed: "older population" OR "older adult*" OR "older people" OR "older group" OR elderly OR aged OR aged [MeSH Terms]) OR elderly [MeSH Terms]).

Scopus: ALL (elderly) OR ALL("older adults") OR ALL(“older population”) OR ALL(“older people”) OR ALL (aged).

The groups were then connected by the Boolean operator "AND"; for Scopus search, the component NOT INDEX (medline) with AND operator was added.

\section{Selection process}

The process of removing duplicates and further records management was conducted using the Mendeley bibliographic program. On both conducted stages of selection ((1) a title and abstract review; (2) a full-text review) the studies were assessed for eligibility independently by two authors. The third author was asked for an additional opinion in the case of conflicting decisions and the majority opinion was decisive.

In the selection process, the inclusion criteria were used as follows: (1) identified problems are related specifically to the QALY measure; (2) identified problems are older age-related; (3) the research applies to broader context, not case-study; and (4) the full text is available in English. The criteria to exclude a study were: (1) identified problems are not related to QALY; (2) identified problems are related to factors other than older age; (3) the research focuses on a specific case, with no generalization possible; (4) the full text is in a language other than English/no full text is available. In line with the methodological framework adopted, no selection was based on a quality assessment [16].

\section{Data extraction}

The data extraction table was designed in accordance with the defined research question. The following fields were included: (1) Author and title; (2) publication year; (3) type of study/methodology used; (4) objective of study; (5) QALY use as a main subject of the study (Y/ $\mathrm{N}$ ); (6) type of problem with QALY indicated; (7) main results/findings; (8) conclusions; (9) recommendations/ solutions proposed.

\section{Results}

\section{Search results}

The database search identified 10,832 relevant items. In the end, 23 of them and nine others from reference lists and other sources (32 in total) were included in the analysis as a result of the search process (Fig. 1).

\section{Overall characteristics of the included studies}

About $40 \%$ of the included studies $(n=13 ; 40.6 \%)$ were published before the year 2000 (four of them before 1990, nine in the years 1990-1999), nine (28.1\%) in the period 2000-2009 and ten (31.3\%) between 2010 and 2018. No studies published after 2018 were found.

In a majority of the included studies $(n=21 ; 65.6 \%)$ the issues regarding the use of the QALY measure for the older population was not a main topic (or even one on the main topics) and comments regarding the topic of interest came up by way of analysing other more or less related problems, such as, for instance, the social value of QALY.

More than $40 \%$ of the analysed studies were original research $(n=13 ; 40.6 \%)$, mostly based on a conducted survey $(n=10 ; 31.3 \%)$. Almost the same number of publications $(n=12 ; 37.5 \%)$ were written as expert opinions, usually based on a more or less advanced argumentative literature review. Only three studies were literature reviews (systematic or narrative).

The problems of using the QALY for the older population indicated in the studies can be divided into six groups (Table 1). Only one of them is directly connected with the saving life year gain component of QALY, but this kind of problem was mentioned in more than half of the analysed studies $(n=17 ; 53.1 \%$; problem 1 in Table 1). In 15 studies, the authors highlighted problems related to the quality of life component of QALY $(n=$ 15; 46.9\%; problems 3-6 in Table 1). In exactly half of the publications ( $n=16 ; 50 \%$; problem 2$)$ an issue associated with an equal valuation of each QALY regardless of age was indicated (not related to the specific QALY component: QoL or length of life). This categorization of problems is used later in this article as a framework for issue analysis.

Only three studies published before the year 2000 indicated problems related to the scope of the measured QoL or to instruments used for its valuation (two regarding instrument aspect (problem 4) and one about health-related QoL measured regardless of age (problem 5)). After the year 2000 these kinds of issues were much more widely discussed and highlighted in 13 publications. An issue associated with the year of life gains component is mentioned in most of the publications in each time period (Fig. 2).

The full list of included studies with more details regarding study characteristics can be found in Table 2 . 

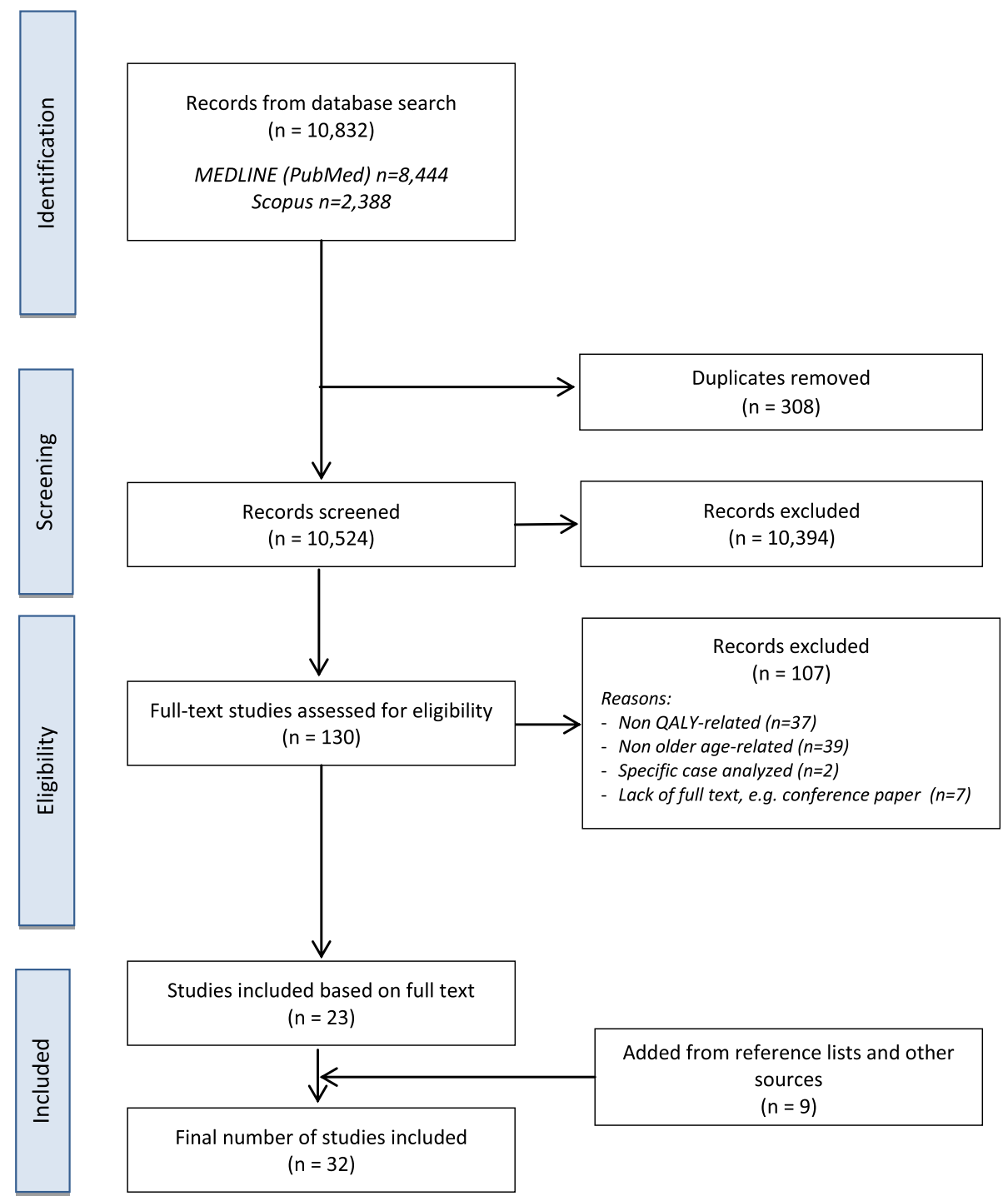

Studies included based on full text $(n=23)$

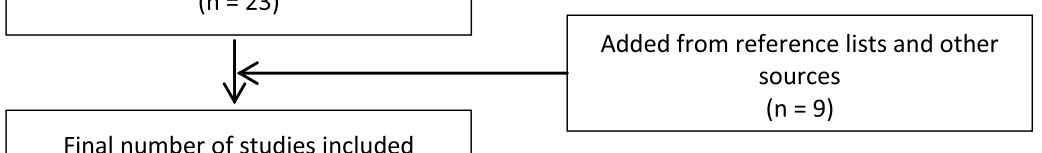

Final number of studies included $(n=32)$

Fig. 1 PRISMA Flow Diagram

Table 1 Types of problems emerging when using QALY for the older population, indicated in the studies

\begin{tabular}{|c|c|c|c|}
\hline Type of problem & Component relationship & $\mathrm{N}^{\mathrm{a}}$ & References \\
\hline 1.Lower life expectancy (LE) causes lower QALY gains (LE) & YoL & 17 & [11-27] \\
\hline 2.Equal value of one $Q A L Y$ regardless of age $(Q=Q)$ & Non specific & 16 & {$[19,20,24,26,28-39]$} \\
\hline 3.Poorer average health state causes lower QALY gains in QoL component (QoL) & QoL & 8 & {$[14,17,18,26,36,39-41]$} \\
\hline 4.QoL measure instrument inadequacy (Instr.) & QoL & 7 & {$[15,17,26,31,40,42,43]$} \\
\hline $\begin{array}{l}\text { 5. Health-related QoL measured regardless of age, while different attributes/attribute } \\
\text { measurements are important for older people (Attrib.) }\end{array}$ & QoL & 5 & {$[20,24,38,40,44]$} \\
\hline 6.No beyond-health QoL aspects taken into account (B-HA) & QoL & 4 & {$[14,40,45,46]$} \\
\hline
\end{tabular}

${ }^{a}$ The sum is not equal to the number of publications as some of them include more than one type of problem YoL years of life, QoL quality of life 


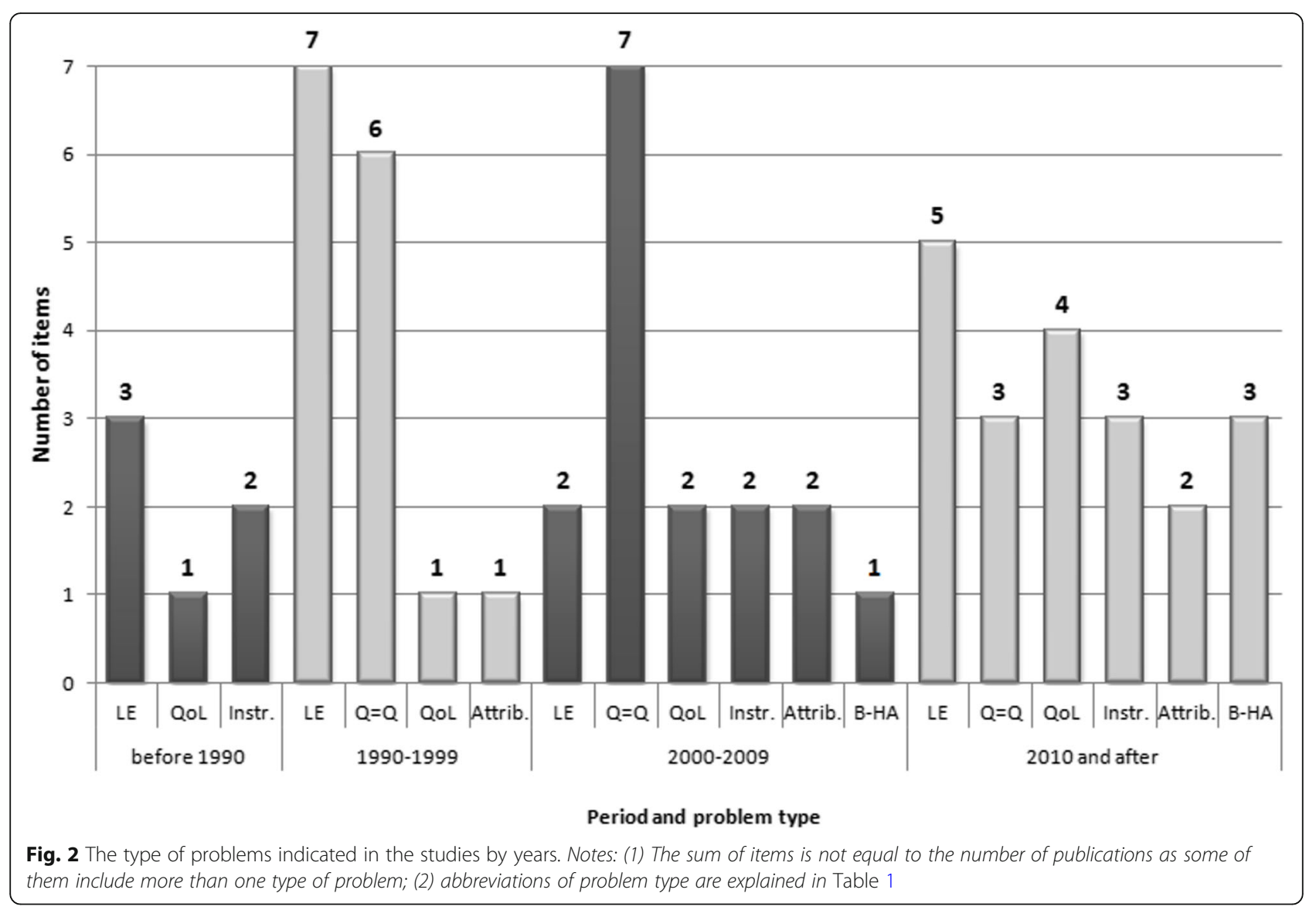

\section{Problems indicated in the studies}

Below, the main findings contained in the included studies are described, according to the type of problem they relate to.

\section{Lower LE causes lower QALY gains}

This most frequently analysed problem (in $53 \%$ of the studies) was that young people undoubtedly have a longer life expectancy than older people. Therefore, in terms of the numbers of life years gained, programmes for the young always (or nearly always) have larger effects than programmes for the old [14, 17, 25]. This problem concerns not only QALY, but all measures based on added years of life. Young people simply have more life years to gain [19-23, 27, 29-31, 40]. This issue can be described as a "ceiling effect" and may bias results against older people [31]. In fact, looking at the concept, age per se is not a cause of potential bias here, but rather LE. However, lower LE is strongly connected with age [24].

Even if the efficacy of a given intervention is the same for the old and the young, the potential duration of effects is lower in older age, due to the lower remaining LE. But this is the case only for long life extension effects - if intervention benefits are relatively short- lasting, gains will be similar [18]. This problem may be of minor importance when an evaluated programme is not only directed at the older population, as in this case, average results for all age groups together are usually taken into account. But if a programme is predominantly for older patients, or analyses are done separately for different age groups, using QALY may lead to discrimination against older people [26].

QALYs will be gained from an intervention over a longer period for the young than for the old, but this issue relates mainly to interventions with short-term costs. For chronic conditions, costs are incurred over a long period of time, so a longer LE means higher costs as well as effects. Therefore, in this case, the discrimination in priority setting against the older population my not be present [28].

\section{Equal value of one QALY regardless of age}

Health in the general QALY concept is valued equally for all people, regardless of age or other individual characteristic. One QALY gained by a young patient is equal to one QALY gained by an old patient - each additional QALY is considered equal, so it is rather an egalitarian than a utilitarian approach [32,36]. As 1 year of a given health is valued equally, formally speaking, QALY is not 
Table 2 The characteristics of included studies

\begin{tabular}{|c|c|c|c|c|}
\hline & Author(s) and year & Type of study & $\begin{array}{l}\text { Is using QALY in older } \\
\text { population a main topic? }\end{array}$ & Type of problem discussed \\
\hline 1 & Asim \& Petrou 2005 [38] & O/AR & $\mathrm{N}$ & $\mathrm{QALY}=\mathrm{QALY} ;$ Attrib \\
\hline 2 & Avorn 1984 [17] & O/AR & $\mathrm{N}$ & LE; QoL; Instr \\
\hline 3 & Baltussen et al.1996 [18] & Rev & $P$ & LE; QoL \\
\hline 4 & Blomqvist 2002 [42] & $\mathrm{R}$ & N & Instr \\
\hline 5 & Brouwer et al. 2005 [39] & $R(S)$ & $\mathrm{N}$ & $\mathrm{QALY}=\mathrm{QALY} ; \mathrm{QOL}$ \\
\hline 6 & Bulamu et al. 2015 [45] & Rev & N & B-HA \\
\hline 7 & Busschbach et al. 1993 [32] & $R(S)$ & Y & $\mathrm{QALY}=\mathrm{QALY}$ \\
\hline 8 & Cookson \& Culyer 2010 [14] & O/AR & $\mathrm{N}$ & LE; QoL; B-HA \\
\hline 9 & Dey \& Fraser 2017 [26] & Rev & $\mathrm{N}$ & LE; QALY = QALY; QoL; Instr \\
\hline 10 & Donaldson et al. 1988 [43] & $\mathrm{R}$ & N & Instr \\
\hline 11 & Franklin 2017 [41] & O/AR & $\mathrm{N}$ & QoL \\
\hline 12 & Grewal et al.2006 [46] & $R(S)$ & N & B-HA \\
\hline 13 & Harris 1987 [27] & O/AR & N & LE \\
\hline 14 & Hazra et al. 2018 [28] & O/AR & $\mathrm{N}$ & $\mathrm{LE} ; \mathrm{QALY}=\mathrm{QALY}$ \\
\hline 15 & Huter et al. 2016 [40] & O/AR & N & LE; QoL; Instr; Attrib; B-HA \\
\hline 16 & Huter et al. 2018 [44] & Rev & $\mathrm{N}$ & Attrib \\
\hline 17 & Johannesson \& Johansson 1996 [29] & $R(S)$ & $\mathrm{N}$ & $L E ; \mathrm{QALY}=\mathrm{QALY}$ \\
\hline 18 & Johannesson \& Johansson 1997 [30] & $R(S)$ & Y & $\mathrm{LE} ; \mathrm{QALY}=\mathrm{QALY}$ \\
\hline 19 & Johri et al. 2005 [31] & $R(S)$ & $P$ & $\mathrm{LE} ; \mathrm{QALY}=\mathrm{QALY} ;$ Instr \\
\hline 20 & Joiner 1999 [19] & O/AR & Y & $\mathrm{LE} ; \mathrm{QALY}=\mathrm{QALY}$ \\
\hline 21 & Kappel \& Sandoe 1992 [20] & O/AR & $P$ & LE; QALY = QALY; Attrib \\
\hline 22 & Kappel \& Sandoe 1994 [21] & O/AR & $P$ & LE \\
\hline 23 & Mendeloff 1983 [22] & O/AR & $\mathrm{N}$ & LE \\
\hline 24 & Nord et al. 1996 [23] & $R(S)$ & $\mathrm{N}$ & LE \\
\hline 25 & Petrou 2014 [33] & Rev & $P$ & $\mathrm{QALY}=\mathrm{QALY}$ \\
\hline 26 & Pettitt et al. 2016 [15] & Rev & Y & Instr \\
\hline 27 & Rodriguez \& Pinto 2000 [34] & $R(S)$ & Y & $\mathrm{QALY}=\mathrm{QALY}$ \\
\hline 28 & Stevens et al. 2012 [25] & Rev & $P$ & LE \\
\hline 29 & Stolk et al. 2005 [35] & $R(S)$ & $\mathrm{N}$ & $\mathrm{QALY}=\mathrm{QALY}$ \\
\hline 30 & Tsuchiya 2000 [36] & $\mathrm{R}$ & $\mathrm{N}$ & QALY = QALY; QoL \\
\hline 31 & Tsuchiya et al. 2003 [24] & $R(S) ; \operatorname{Rev}$ & N & LE; QALY = QALY; Attrib \\
\hline 32 & Williams 1997 [37] & $\mathrm{O} / \mathrm{AR}$ & $\mathrm{N}$ & $\mathrm{QALY}=\mathrm{QALY}$ \\
\hline
\end{tabular}

Legend:

Type of study

- O/AR: authors' opinions, also based on an argumentative review

- $R(S)$ : research based on survey

- $R$ : other than survey research

- Rev: systematic or narrative literature review

Is using QALY in the older population a main topic?

- N: no

- $P:$ it is one of the main topics of the study, but not the only

- $Y$ : yes

Type of problem discussed

- Attrib:: QoL measured regardless of age, while different attributes/attribute measures are important for the older population

- B-HA: no beyond-health QoL aspects taken into account

- Instr:: problems with inadequacy of QoL measurement instrument

- LE: lower LE causes lower QALY gains

- $Q A L Y=Q A L Y$ : equal value of one QALY regardless of age

- QoL: poorer average health state causes lower QALY gain 
ageist [20]. However, there is a doubt as to whether one QALY should indeed be valued the same for the young as for the old [19, 24, 34, 35, 37, 38].

The equal valuation of QALY, regardless of age often seems inconsistent with general public preferences, as society would place different values on health gained at different stages of life: in general, the social value of health is often found to be higher for younger people than for older people [26, 29, 30, 32]. In line with this point of view, assuming equal QALY values can be a problem when comparing QALY gains for the young and the old.

Arguments against QALY equality in terms of age can be various. One of them is the "fair-innings" concept which assumes that every person should have an equal chance of living "a normal" life meaning "normal" length and quality. As older people have already attained a larger share of their "fair innings", the younger population should receive more health care currently. "Fair innings" assumes that the social value of health benefits is based not only on the efficiency criterion, but also distributive context matters $[28,31,35,36]$. However, it is not a rule that people living to advanced ages used more health care earlier in life - they might have used a minimal amount, but expect to benefit more from the health system in older age. Living a "fair share" of life doesn't always mean receiving a "fair share" of health care [28].

There is growing evidence that people give a higher value to health gains for the young, but many methodological constraints in research in this area still exist $[33,34]$. The intervention type may also matter in terms of general public assessment: age is important when it comes to life-saving intervention, but much less important in terms of pain relief or depression [31].

One more argument against QALY equality for all is the level of acceptable health state. It may be varied for different ages, so one QALY when one is young is not the same as one QALY when one is old if the acceptable level of health (lower than ideal) is considered maximal for the latter [39].

The above may have consequences for QALY analysis: in general, people consider health of younger people to be more valuable than the health of older people, while in the general QALY concept, the value is weighted the same for each age group. On one hand, the QALY analysis creates differences based on effectiveness of treatment (which is often lower for older people), but on the other hand, it does not take into account differences between people and social preferences regarding it. QALY analysis can be seen then as more egalitarian than the general public prefers [32].

\section{Poorer average health state causes lower QALY gains in the QoL component}

Each method of evaluating gains in QoL may discriminate based on disability [26]. The quality of life is usually lower in older age (e.g., because of comorbidities), so even if the same number of years is saved for a young and an old person, using QALY methodology, the latter will be valued as less beneficial. An intervention, even when completely successful, does not improve the health of an older person with co-morbidities to the level of ideal health [14, 17, 40]. "Full health" is seen as full psychophysical function, but this can be problematic in the case of patients with a permanent disability and comorbidities, which frequently emerge in older age. An intervention can only limit their disability, but "full health" state, as defined in the QALY methodology, is impossible to achieve. As a result, QALY gains for such people is evaluated lower [41]. A fully successful health intervention in the case of older people result in smaller QALY gains then for younger people, as the maximal possible QoL is lower, older people may respond less to a treatment, more complications occur, and the capacity to recover is simply limited $[18,36]$.

At different ages there can be different meanings of "good health". A "perfect health equals 1" is used in the standard QALY calculation as a reference point for health gains. As a consequence, the fact that this ideal level of health is not possible (or is more often not possible) to reach in the case of older people may cause an incorrect estimation of health effects. People adapt to reduced health states as they become older and as they link their health assessment to that of similar groups rather than to perfect health, they are willing to accept a worse health state as "normal". Research has confirmed that the acceptance of a lower than perfect level of health increases with age (with differences depending on the health domain: for instance, some health problems, such as reduced mobility, had the highest level of acceptability, while anxiety/depression was very often considered unacceptable even in older age). So from the societal perspective, the same health gain may be differently valued, depending on a given individual's level of accepted health state [39].

For long-term care, more often provided to the older population, the goal would be to slow down the loss of QoL rather than to increase QoL - whereas for acute care, the goal is to improve it. This differentiation of the attitude to health interventions effects can be important when comparing effectiveness [26].

\section{QoL measurement instrument inadequacy}

Answering standard-gamble or similarly constructed questions individuals can take into account expected life-time budget constraints connected with a given 
health state. Young people are likely to accept a relatively large decrease in expected life years in order to compensate for a given decrease in quality, as they take into account the potential necessity of consumption reduction in the case of ill health when young (a reduction in youth and, consequently, in old age as well). A different approach of young and old to issues related to the potential financial consequences may result in a bias against older in allocation decisions [42].

Very ill people often value their QoL differently than healthy people asked to assess the same health state. For older groups, it is increasingly often not possible to use patient-based data to determine numerical values of health states, as many diseases (e.g., dementia) limit contact with patients [17]. Basing the quality assessment on a different type of data source can cause problems in comparability.

Long-term care, more often provided to older people, may have a minimal impact on health, and the potential for health gains is often limited in old age. If the instruments used to measure QoL changes are not sensitive enough to measure these small changes (as is often a case), the QALYs gain is small when compared to more acute forms of care, or even equal to zero $[15,26,31,40,43]$.

\section{Health-related QoL measured regardless of age}

The QALY is linked to health-related QoL, valued on the basis of the preferences of a tested group of people and determined independently of any other features (like age, for instance) [20]. The QALY method assumes that changes in QoL caused by a given treatment are independent of age, but in fact, QoL resulting from the same health condition can differ for the young and the old. It is not clear whether for some age groups it is lower or higher - older people can value their health less, but on the other side, can also start to expect more from life and perceive good health as more important [20]. The research of Tsuchiya et al. indicates that some health problems can cause a larger loss of QoL to a younger person than to older person [24]. In any case, significant differences between the young and the old may emerge.

One QoL measure that is the same for all groups may not correspond to people's experiences and expectations, as various factors/attributes influence health-related quality of life and do so in different ways. Some attributes of health-related QoL may become more or less important with increasing age, as preferences change in the course of life; e.g., mobility, crucial for the young, may be of less significance for older people, as a certain range of restrictions in this area is accepted and considered normal in old age. Therefore, a loss of QoL caused by the same bad health state and, accordingly, a gain of QoL obtained as a result of an intervention can be valued totally different at different ages. The measurement of QoL for older people needs to be more focused on the health-related ability to undertake the activities of daily living and the capability to achieve different functions. The currently used preference-based utility measures are not in line with the real needs of older people [38, 40, 44].

\section{No beyond-health QoL aspects taken into account}

The instruments used to assess the QoL component in QALY calculation limit this assessment to dimensions related to health-related QoL. Whereas, for old people, aspects other than those related to health are often essential. It is sometimes difficult to separate health needs from social needs in the older population. Moreover, social values (integration into the community, inclusion, relationships) may be even more important than health improvements per se [40]. Independence, psychological wellbeing, social relations, standard of living, and social activities are examples of factors that strongly influence older people's quality of life [46]. As the concept of quality of life is more multi-dimensional for the elderly people and it is not only defined by health status, it should be measured by taking into account a broad range of dimensions, not only health status and/or functionality [45]. As the outcomes measured by QALY do not include non-health dimensions, overall social welfare is not actually assessed, but only overall population health [14]. A single preference-based instrument of QoL measurement, which could incorporate health status as well as other aspects of quality of life which are important for older people has not yet been constructed $[40,45]$.

\section{How can these issues be solved?}

Some authors of the included publications indicated various modifications that could improve the QALY method. These changes could potentially be used to solve or at least to mitigate the effects of problems with using QALY for the older population. The summary of these proposals is presented in Table 3.

\section{Discussion}

The QALY method can be used to help make a decision regarding which treatment/health activities should be provided to a given group of people or to which group of people care should be provided. The latter is much more problematic when it requires comparing the health gains in different age groups, especially if one of them is the older population. Our review showed an abundance of literature in which problems related to the use of QALY for older people are mentioned. These problems can be classified into six general categories, described in the article: (1) lower life expectancy in the old population causes lower QALY gains; (2) an equal value of one 
Table 3 The solutions of indicated problems suggested in the studies

\begin{tabular}{|c|c|c|}
\hline Type of problem & Potential solution & Remarks \\
\hline \multirow[t]{2}{*}{ Lower QALY caused by lower LE } & $\begin{array}{l}\text { Introducing "end-of-life" rule (higher valuation of } \\
\text { gained years in the case of terminal illnesses with no } \\
\text { more than } 2 \text { years to live) [25]. }\end{array}$ & $\begin{array}{l}\text { When the EOL rule is implemented, age discrimination } \\
\text { can only emerge under very rare conditions [25]. }\end{array}$ \\
\hline & $\begin{array}{l}\text { Introducing discounting: gains of life years are } \\
\text { diminished when they occur in the distant future [18]. }\end{array}$ & $\begin{array}{l}\text { Discounting greatly reduces the problem, and may } \\
\text { make it almost negligible [18]. }\end{array}$ \\
\hline $\begin{array}{l}\text { Equal value of QALY regardless of } \\
\text { age }\end{array}$ & $\begin{array}{l}\text { To adjust the results of QALY analysis to better match } \\
\text { general public opinion by introducing age-correction } \\
\text { (age weighting of QALY) [28, 30-33, 35, 37]. }\end{array}$ & $\begin{array}{l}\text { The problem is too complex to be solved by age- } \\
\text { weights [31]. } \\
\text { Research mainly focused on life-saving interventions } \\
\text { may wrongly interpret social preferences [31]. } \\
\text { Future research should be conducted before } \\
\text { introducing such a solution, also combining age with } \\
\text { other factors like gender or socio-economic status [30, } \\
\text { 33]. } \\
\text { More equitable distribution will cause lower efficiency } \\
\text { [37]. } \\
\text { Such weights may become arbitrary and give the } \\
\text { possibility of abuse [37]. }\end{array}$ \\
\hline \multirow[t]{2}{*}{$\begin{array}{l}\text { Lower gains in QoL possible for } \\
\text { older people }\end{array}$} & $\begin{array}{l}\text { Determining different thresholds of QALY accepted } \\
\text { for financing for different age groups [40]. }\end{array}$ & $\begin{array}{l}\text { Not a sufficient solution } \\
\text { if all dimensions important for older people's QoL are } \\
\text { not taken into account at the same time [40]. }\end{array}$ \\
\hline & $\begin{array}{l}\text { Calibration of health state valuation to best attainable } \\
\text { health prospect [41]. }\end{array}$ & \multirow[t]{2}{*}{$\begin{array}{l}\text { No motivation for seeking methods to improve a } \\
\text { health state level which is deemed "normal" [41]. }\end{array}$} \\
\hline $\begin{array}{l}\text { QoL measure instrument } \\
\text { inadequacy }\end{array}$ & $\begin{array}{l}\text { Developing a proper age-specific preference-based in- } \\
\text { dicator for QoL measurement }[40,46] \text {. }\end{array}$ & \\
\hline \multirow[t]{3}{*}{$\begin{array}{l}\text { Health-related QoL measured } \\
\text { regardless of age; no beyond-health } \\
\text { QoL aspects taken into account }\end{array}$} & $\begin{array}{l}\text { Using EQ-5D in combination with another instrument } \\
\text { suitable for older people (e.g. ICECAP-O or ASCOT) } \\
\text { [45]. }\end{array}$ & \multirow{3}{*}{$\begin{array}{l}\text { There is no single existing measure that could assess } \\
\text { QoL in a sense broad enough for older people [45]. } \\
\text { Further research is needed to identify relevant } \\
\text { attributes of health-related QoL for different age } \\
\text { groups [38]. }\end{array}$} \\
\hline & $\begin{array}{l}\text { Developing a new, age-specific measure of QoL, tar- } \\
\text { geted at older people, based more on capability than } \\
\text { functioning and preference-based utility }[40,46] \text {. }\end{array}$ & \\
\hline & $\begin{array}{l}\text { To allocate budget separately for different levels of } \\
\text { care and beneficiaries' age, using appropriate } \\
\text { assessment criteria [26]. }\end{array}$ & \\
\hline
\end{tabular}

Authors' indication of a potential solution does not always mean that they consider it a recommendation

QALY is used regardless of age; (3) a poorer average health state causes lower QALY gains; (4) inadequate quality of life (QoL) measurement instruments; (5) attributes of QoL used regardless of age; and (6) no beyondhealth QoL aspects taken into account. Although the problems seem to be clearly defined and quite well recognized, the potential solutions are much more ambiguous. Numerous authors emphasize the need for further research and consensus building activities in order to define recommendations.

The maximization of QALY does not offer the best solution to resource allocation problems, but even if QALY is not an ideal measure, this method might be seen as the best available and does have a lot of supporters [19, $20,36]$. QALY only indicates the option with the largest gain in population health, but there is no indication of which decision brings the highest overall social value [14]. Due to many limitations, QALY may be seen as not fully suitable for assessing health outcomes for older people, and its use is controversial. Many different ways to mitigate the problems that come with using QALY have been proposed (Table 2), but finding a widely accepted solution is a very difficult task.

There are different points of view and opinions regarding the possible ageist bias of QALY: one says that QALY discriminates against older people, the other says that it does not discriminate. Some experts even argue that QALY rather discriminates against young people and is not ageist enough [20,30]. In QALY definition, the age of the person under consideration is not directly taken into account and this can, on first sight, be seen as a form of equality [29]. However, as presented above, after deeper analysis, many issues with equality may be identified.

Achieving allocative efficiency may not be socially favourable. The method using QALY assumes the primacy of health maximization; however, societal preferences demonstrate that other characteristics may affect priority setting $[28,35]$. Some research indicates that due to general public opinion, especially in the case of life-saving/emergency treatment, younger people should receive priority over older people (e.g., [30, 32, 47, 48]. 
However, for treatment which improves quality of life rather than saving life, no such priorities are given [49]. What is interesting is that the opinion regarding valuing $f$ younger people's health more than older people's does not change with age - younger and older people's opinions are similar $[30,32,48]$. So in some cases, and to some extent, lower QALY gain in older age can be in line with social values, focusing health programmes on children and younger people [14]. Looking at social preferences, it can be stated that a bias may also occur sometimes in favour of older people, and health gains should be weighted, but rather giving lower weights to benefits in older age (e.g. [24, 26, 31, 34, 49]. Various possible reasons for valuing the health of the young more than that of the old can be indicated: (1) the impact of health in younger age on the whole development of an individual (health problems can have more than immediate consequences, but also future consequences); (2) more responsibility for others (e.g., for children); and (3) younger people can be seen as more valuable for society (productivity ageism) [9]. Even if we agree that in some cases the young should have some priority in receiving health care over the old, the problem gets more serious when it is necessary to set how much more priority should be given. Assigning age-weights may be seen as the best solution to, in a way, integrate efficiency and equity consideration. But such weights may become arbitrary and create the possibility for abuse, rather than achieving the desired results [37].

One important step in the QALY calculation is the valuation of QoL, often indicated as a problematic process. The perception of QoL in this case is usually limited to health aspects, but there is an ongoing discussion regarding the need for a broader approach to this quality, focused more on overall "well-being", in order to better capture the full benefits of activities [7, 50]. An overly narrow understanding of the QoL may lead to underestimations of effects, especially in older populations. Developing a new measure, containing more than just health-related attributes, would make it possible to compare the full value of interventions, which would improve QoL by focusing impact on more than only health, which is often important with the older people [51].

Our review has provided a systematic overview of the literature related to the problems (and potential solutions to those problems) of applying the QALY measure to assess interventions for older people. To the authors best knowledge, it is the first study of this kind. Yet, it is not free from limitations. Due to feasibility of the work, we have used only two databases for the initial search, including full texts solely in English. This review has been limited to publications regarding the problems of using QALY for the older population. However, many issues which occur in the case of people with disabilities or in the last years of life may be similar or even identical, so further analysis should take into account more broadly defined groups of people in order to identify more potential problems. Additionally, some more issues regarding the analysed problems could possibly be found by directly checking studies on the QoL measurement methods typically used in QALY calculation (e.g., the Standard Gamble or Time Trade-off). The portions of publications concerning them may not directly point to QALY and, therefore, may not have been found in this search. Despite these limitations we believe we have provided a comprehensive overview and analytical framework for further investigations.

Life expectancy is still increasing, the health expectations of older people are changing, and so is the perception of older people in society. So, more current research is needed to better understand the health needs of older people and how to be more efficient in meeting them. Considering equity in allocation decisions, especially in the face of scarce resources, is a really challenging task, as health-care distribution will always include some degree of discrimination [19]. The concept of equity is very multi-dimensional, may be viewed subjectively, and can indicate inefficient solutions. To maintain the balance between efficiency and equity, issues connected with age-based rationing should be widely discussed.

\section{Conclusions}

QALY is the most used measure of health effects and has been widely recommended so far, but this does not mean that nothing in this methodology can be improved. This review clearly shows that many problems of different types are connected with using QALY for the older population, but there is no consensus as to whether QALY discriminates against older people or not - one's opinion regarding this issue depends strongly on accepted principles, particularly one's approach to equity and how one understands fairness. QALY should be used for the older population with caution and further research is needed to improve methods in order to help make the best allocation decisions.

\section{Abbreviations \\ CUA: Cost-utility analysis; LE: Life expectancy; QALY: Quality Adjusted Life Year; QoL: Quality of life: YoL: years of life}

\section{Acknowledgements}

Not applicable.

\section{Authors' contributions}

All authors meet the authorship criteria and agree to the submission of the manuscript. Conceptualization: EK; methodology: EK, KD-J; search: EK; screening for inclusion/exclusion: EK, PK, with support from KD-J; data extraction: EK, PK; data synthesis: EK, findings interpretation, manuscript writing: EK; manuscript review and revision: EK, KD-J. 


\section{Funding}

Open access funding provided by the Jagiellonian University Medical College through Statutory Program N43/DBS/000125.

\section{Availability of data and materials}

Full data and material available upon request.

\section{Declarations}

\section{Ethics approval and consent to participate}

Not applicable.

\section{Consent for publication}

Not applicable.

\section{Competing interests}

E. Kocot, P. Kotarba, and K. Dubas-Jakóbczyk declare that they have no competing interest.

\section{Author details}

${ }^{1}$ Health Economics and Social Security Department, Institute of Public Health, Faculty of Health Sciences, Jagiellonian University Medical College, Krakow, Poland. ${ }^{2}$ Department of Health, Małopolska Provincial Office in Krakow, Krakow, Poland.

\section{Received: 22 July 2021 Accepted: 5 November 2021}

Published online: 18 November 2021

\section{References}

1. Siegel JE, Weinstein MC, Russell LBGM. Recommendations for reporting cost-effectiveness analyses. Panel on cost-effectiveness in health and medicine. JAMA. 1996;276:1339-41. https://doi.org/10.1001/jama.276.1 6.1339.

2. Neumann PJ, Greenberg D, Olchanski NV, Stone PWRA. Growth and Quality of the Cost-Utility Literature, 1976-2001. Value Health. 2005;8:3-9. https:// doi.org/10.1111/j.1524-4733.2005.04010.x.

3. Davis JC, Liu-Ambrose T, Khan KM, Robertson MC, Marra CA. SF-6D and EQ$5 \mathrm{D}$ result in widely divergent incremental cost-effectiveness ratios in a clinical trial of older women: implications for health policy decisions. Osteoporos Int England. 2012;23:1849-57. https://doi.org/10.1007/s00198011-1770-3.

4. EUNETHA. Methods for health economic evaluations-a guideline based on current practices in Europe. Guideline. 2015

5. Schwappach DLB. Resource allocation, social values and the QALY: a review of the debate and empirical evidence. Heal Expect Blackwell Publishing Ltd. 2002:210-22. https://doi.org/10.1046/j.1369-6513.2002.00182.x.

6. Attema AE, Brouwer WBF, L'Haridon O, Pinto JL. Estimating sign-dependent societal preferences for quality of life. J Health Econ Netherlands. 2015;43: 229-43. https://doi.org/10.1016/j.jhealeco.2015.07.006.

7. van de Wetering EJ, van Exel NJA, Rose JM, Hoefman RJ, Brouwer WBF. Are some QALYs more equal than others? Eur J Heal Econ. 2016;17:117-27. https://doi.org/10.1007/s10198-014-0657-6.

8. Dolan P, Shaw R, Tsuchiya A, Williams A. QALY maximisation and people's preferences: a methodological review of the literature. Health Econ. 2005;14: 197-208. https://doi.org/10.1002/hec.924.

9. Cookson R, Drummond $M$, Weatherly $H$. Explicit incorporation of equity considerations into economic evaluation of public health interventions. Heal Econ Policy Law. 2009:4:231-45. https://doi.org/10.1017/S17441331 09004903.

10. Hines PA. Is quality-adjusted life years ( QALY) terminal ? A literature review into QALY's criticisms. Albanian Med J. 2015;1:72-8.

11. Duru G, Auray JP, Béresniak A, Lamure M, Paine A, Nicoloyannis N. Limitations of the methods used for calculating quality-adjusted life-year values. Pharmacoeconomics Adis International Ltd. 2002;20:463-73. https:// doi.org/10.2165/00019053-200220070-00004.

12. Herlitz A. Against lifetime QALY prioritarianism. J Med Ethics BMJ Publishing Group. 2018:44:109-13. https://doi.org/10.1136/medethics-2017-104250.

13. Borissov B. Current controversies of using cost per QALY for costeffectiveness analysis-Isn't two decades enough? Biomed res Clin Pract. Open Access Text Pvt, Ltd. 2019;4. https://doi.org/10.15761/BRCP.1000191.
14. Cookson R, Culyer A. Measuring overall population health: the use and abuse of QALYs. Evid Based Public Heal Eff Effic. 2010. https://doi.org/10.1 093/acprof:oso/9780199563623.003.010.

15. Pettitt DA, Raza S, Naughton B, Roscoe A, Ramakrishnan A, Ali A, et al. The limitations of QALY : a literature review. J Stem Cell Res Ther. 2016;6. https:// doi.org/10.4172/2157-7633.1000334

16. Peters MDJ, Godfrey CM, Khalil H, Mclnerney P, Parker D, Soares CB. Guidance for conducting systematic scoping reviews. Int J Evid Based Healthc. 2015:13:141-6. https://doi.org/10.1097/XEB.0000000000000050.

17. Avorn J. Benefit and cost analysis in geriatric care. N Engl J Med. 1984;310: 1294-301. https://doi.org/10.1056/NEJM198405173102005.

18. Baltussen $R$, Leidl $R$, Ament $A$. The impact of age on cost-effectiveness ratios and its control in decision making. Health Econ England. 1996;5:227-39. https://doi.org/10.1002/(SICI)1099-1050(199605)5:3\%3C227::AID-HEC198\%3E3. $0 . \mathrm{CO} ; 2-\mathrm{Y}$.

19. Joiner A. Quality adjusted life years and the allocation of health care to the elderly: ethical considerations. J Orthop Nurs. 1999;3:81-4. https://doi.org/1 0.1016/S1361-3111(99)80029-6.

20. Kappel K, Sandoe P. QALYS, age and fairness. Bioethics England. 1992:6:297316. https://doi.org/10.1111/j.1467-8519.1992.tb00208.x.

21. Kappel K, Sandoe P. Saving the young before the old -- a reply to John Harris. Bioethics England. 1994;8:84-92. https://doi.org/10.1111/j.1467-8519.1 994.tb00243.x.

22. Mendeloff J. Measuring elusive benefits: on the value of health. J Health Polit Policy Law United States. 1983;8:554-80. https://doi.org/10.1215/0361 6878-8-3-554.

23. Nord E, Street A, Richardson J, Kuhse H, Singer P. The significance of age and duration of effect in social evaluation of health care. Health Care Anal Netherlands. 1996:4:103-11. https://doi.org/10.1007/BF02251210.

24. Tsuchiya A, Dolan P, Shaw R. Measuring people's preferences regarding ageism in health: some methodological issues and some fresh evidence Soc Sci Med Soc Sci Med. 2003:57:687-96. https://doi.org/10.1016/S0277-953 6(02)00418-5.

25. Stevens A, Doyle N, Littlejohns P, Docherty M. National institute for health and clinical excellence appraisal and ageism. J Med Ethics. 2012;38:258-62. https://doi.org/10.1136/medethics-2011-100129.

26. Dey I, Fraser N. Age-based rationing in the allocation of health care. Elder leg ethical issues Healthc. Policy. 2017:501-27. https://doi.org/10.1177/08982 6430001200404

27. Harris J. QALYfying the value of life. J Med Ethics Institute of Medical Ethics. 1987;13:117-23. https://doi.org/10.1136/jme.13.3.117.

28. Hazra NC, Gulliford MC, Rudisill C. "Fair innings" in the face of ageing and demographic change. Health Econ Policy Law England. 2018;13:209-17. https://doi.org/10.1017/S1744133117000329.

29. Johannesson M, Johansson PO. The economics of ageing: on the attitude of Swedish people to the distribution of health care resources between the young and the old. Health Policy Ireland. 1996;37:153-61. https://doi.org/1 0.1016/s0168-8510(96)90022-6.

30. Johannesson $M$, Johansson PO. Is the valuation of a QALY gained independent of age? Some empirical evidence. J Health Econ Netherlands. 1997:16:589-99. https://doi.org/10.1016/s0167-6296(96)00516-4.

31. Johri M, Damschroder LJ, Zikmund-Fisher BJ, Ubel PA. The importance of age in allocating health care resources: does intervention-type matter? Health Econ England. 2005;14:669-78. https://doi.org/10.1002/hec.958.

32. Busschbach JJV, Hessing DJ, De Charro FT. The utility of health at different stages in life: a quantitative approach. Soc Sci Med. 1993;37:153-8. https:// doi.org/10.1016/0277-9536(93)90451-9.

33. Petrou S. Methodological and applied concerns surrounding age-related weighting within health economic evaluation. Expert Rev Pharmacoecon Outcomes Res England. 2014;14:729-40. https://doi.org/10.1586/14737167.2 014.940320 .

34. Rodriguez E, Pinto JL. The social value of health programmes: is age a relevant factor? Health Econ England. 2000;9:611-21. https://doi.org/10.1 002/1099-1050(200010)9:7\%3C611:*aid-hec540\%3E3.0.co;2-r.

35. Stolk EA, Pickee SJ, Ament AHJA, Busschbach JJ V. Equity in health care prioritisation: an empirical inquiry into social value. Health Policy Ireland; 2005;74:343-355. https://doi.org/https://doi.org/10.1016/j.hea Ithpol.2005.01.018.

36. Tsuchiya A. QALYs and ageism: philosophical theories and age weighting. Health Econ England. 2000;9:57-68. https://doi.org/10.1002/(sici)1099-1050(2 00001)9:1\%3C57::aid-hec484\%3E3.0.co;2-n. 
37. Williams A. Intergenerational equity: an exploration of the "fair innings" argument. Health Economics. 1997;6:117-132. https://doi.org/10.1002/(sici)1 099-1050(199703)6:2<117::aid-hec256>3.0.co;2-b.

38. Asim O, Petrou S. Valuing a QALY: review of current controversies. Expert Rev Pharmacoeconomics Outcomes Res. 2005;5:667-9. https://doi.org/10.1 586/14737167.5.6.667.

39. Brouwer WBF, van Exel NJA, Stolk EA. Acceptability of less than perfect health states. Soc Sci Med England. 2005;60:237-46. https://doi.org/10.1016/ j.socscimed.2004.04.032.

40. Huter K, Kocot E, Kissimova-Skarbek K, Dubas-Jakobczyk K, Rothgang H. Economic evaluation of health promotion for older people-methodological problems and challenges. BMC Health Serv Res England. 2016;16(Suppl 5): 328. https://doi.org/10.1186/s12913-016-1519-y.

41. Franklin D. Calibrating QALYs to respect equality of persons. Utilitas. 2017; 29:65-87. https://doi.org/10.1017/S0953820816000194.

42. Blomqvist A. QALYs, standard gambles, and the expected budget constraint. J Health Econ Netherlands. 2002;21:181-95. https://doi.org/10.1016/s0167-62 96(01)00116-3.

43. Donaldson C, Atkinson A, Bond J, Wright K. Should QALYs be programmespecific? J Health Econ Netherlands. 1988;7:239-57. https://doi.org/10.1016/ 0167-6296(88)90027-6.

44. Huter K, Dubas-Jakóbczyk K, Kocot E, Kissimova-Skarbek K, Rothgang H. Economic evaluation of health promotion interventions for older people: do applied economic studies meet the methodological challenges? Cost Eff Resour Alloc. 2018;16. https://doi.org/10.1186/s12962-018-0100-4.

45. Bulamu NB, Kaambwa B, Ratcliffe J. A systematic review of instruments for measuring outcomes in economic evaluation within aged care. Health Qual Life Outcomes BioMed Central Ltd. 2015. https://doi.org/10.1186/s12955-01 5-0372-8.

46. Grewal I, Lewis J, Flynn T, Brown J, Bond J, Coast J. Developing attributes for a generic quality of life measure for older people: preferences or capabilities? Soc Sci Med. 2006;62:1891-901. https://doi.org/10.1016/j. socscimed.2005.08.023.

47. Lewis PA, Charny M. Which of two individuals do you treat when only their ages are different and you can't treat both? J Med Ethics. 1989;15:28-32

48. Cropper ML, Aydede SK, Portney PR. Preferences for life saving programs: how the public discounts time and age. J Risk Uncertain Kluwer Academic Publishers. 1994;8:243-65. https://doi.org/10.1007/BF01064044.

49. Nord E, Pinto JL, Richardson J, Menzel P, Ubel P. Incorporating societal concerns for fairness in numerical valuations of health programmes. Health Econ. 1999;8:25-39. https://doi.org/10.1002/(sici)1099-1050(199902)8:1\%3C2 5::aid-hec398\%3E3.0.co;2-h.

50. Makai P, Brouwer WBF, Koopmanschap MA, Stolk EA, Nieboer AP. Quality of life instruments for economic evaluations in health and social care for older people: a systematic review. Soc Sci Med Elsevier Ltd. 2014:83-93. https:// doi.org/10.1016/j.socscimed.2013.11.050

51. Coast J, Flynn TN, Natarajan L, Sproston K, Lewis J, Louviere JJ, et al. Valuing the ICECAP capability index for older people. Soc Sci Med. 2008;67:874-82. https://doi.org/10.1016/j.socscimed.2008.05.015.

\section{Publisher's Note}

Springer Nature remains neutral with regard to jurisdictional claims in published maps and institutional affiliations.

Ready to submit your research? Choose BMC and benefit from:

- fast, convenient online submission

- thorough peer review by experienced researchers in your field

- rapid publication on acceptance

- support for research data, including large and complex data types

- gold Open Access which fosters wider collaboration and increased citations

- maximum visibility for your research: over $100 \mathrm{M}$ website views per year

At BMC, research is always in progress.

Learn more biomedcentral.com/submissions 